\title{
Effects Of Market Orientation And Barriers To Market Orientation On University Performance: A Study Of Universities Of Technology In South Africa
}

Bakae Aubrey Mokoena, Vaal University of Technology, South Africa Manilall Roy Dhurup, Vaal University of Technology, South Africa

\begin{abstract}
Market orientation has been illuminated as a critical component in shaping an institution's success. While marketing orientation is embedded within the philosophical foundation of marketing, its operationalisation does not automatically translate in university success as there are various constraints, which impede its implementation. The objective of the study is to examine the influence of market orientation and the current barriers to market orientation on university performance among universities of technology (UoTs) in South Africa. This paper employs a crosssectional quantitative survey. Data from a convenient sample of 507 academics in five UoTs are analysed. Through confirmatory factor analysis and structural model analysis, these relationships are discerned and explained. The findings of the study support theoretical arguments that higher education institutions (HEIs) can be successful in terms of their performance by initiating and adopting market-oriented activities. This study contributes to the critical challenge facing UoTs as a new type of HEI within a South African context in creating a culture and climate that maximises organisational learning, resource utilisation and capabilities to create superior university performance. Based on the findings, limitations and implications for further research are also provided. Management of UoTs can also enhance performance of their institutions by implementing key recommendations that the study advances.
\end{abstract}

Keywords: HEIs, UoTs, Market Orientation; Barriers To Market Orientation; University Performance

\section{INTRODUCTION}

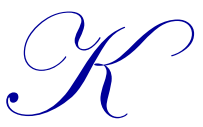

otler (1972) has long argued that market orientation is relevant to not only profit-making organisations but also to non-profit organisations. Literature on higher education (HE) marketing focuses on various aspects starting with the educational marketplace (Brown \& Scott, 2006; Hanover, 2014; Kumar \& Hurwitz, 2015) and moving on to specific topics such as the marketing mix and educational marketing strategies (Ivy, 2008; Schuller \& Rasticova, 2011; Gajić 2012), marketisation of universities (Kusumawati 2010; Molesworth, Scullion \& Nixon, 2011; Brown \& Carasso 2013; Brown 2015; Felgueira \& Rodrigues 2014), and recently a dynamic evolution from the marketing concept to the market orientation (Ionescu 2015; Hussain, Shah \& Akhtar 2016).

According to Becher, Halstead and Haynes (2003), market orientation refers to a culture in which organisations strive to create superior performance for the organization by focusing on customer needs and long-term profitability. The idea of market orientation contributing to an organisation's performance has been highlighted across various businesses in differing stages of growth and maturity. This relationship between market orientation and business performance has been investigated and implemented in various contexts. In this regard, a performance-oriented university is critical in meeting national current and future development needs. The implementation of market orientation within HEIs arena is also in line with the vision of ensuring quality issues and links to the market and students' needs.

Although market orientation is critical in HEIs for its influence on performance, several barriers impede its adoption and implementation. According to Dubihlela \& Dhurup (2015), barriers to the implemention of market orientation 
continue to beset the marketing discipline and there is much evidence thereof (Mokoena, Mafini \& Dhurup 2015). It is worth mentioning that the available literature identifies numerous barriers to the implementation of market orientation that are complex and interrelated. Therefore, a better understanding of the types of barriers to market orientation within HEIs and how they can be explained in the context of UoTs, is critical.

Key research themes relevant to the study of market orientation of higher education institutions (HEIs) are the components of market orientation, the barriers in the implementation of market orientation and the consequences thereof on institutional success.

\section{PROBLEM STATEMENT AND STUDY OBJECTIVES}

Although it is recognised that market orientation has been adopted, UoTs have not yet reached a stage where a full marketing attitude has been developed. Three reasons can be cited in support of this statement. First, the failure of these HEIs to domesticate the marketing idea and turn it into a homegrown philosophy by utilising marketing ideas based on borrowed wisdom from the business sector. Secondly, that current HE marketing lacks an appropriate contextualisation. It is poorly organised and coordinated, largely responsive, not strategic and its application lacks formal operational guidelines.

Thirdly, among the challenges facing HEIs is competition between universities for both resources and students, which is believed to lead to a shift in the institutions' focus towards its offering (Camella \& Marius 2013). With new types of HEIs created in South Africa, on one end of the continuum, comprehensive universities, and the other end, standalone UoTs, students are now faced with a broader selection of HEIs, all competing with one another. There is lack of empirical and conceptual studies on the influence of market orientation and its associated barriers among HEIs in South Africa. This research attempts to address this gap and contribute to the market orientation and university performance literature.

Hence, the purpose of this paper is to provide a short literature review on the constructs under investigation and to examine the impact of market orientation and its associated barriers on university performance.

\section{LITERATURE REVIEW}

\section{Market Orientation}

Market orientation is described as a method of contributing towards better management of organisations, thus enabling managers to focus on external and internal elements, which impact on the activities of an organisation's quest in performance improvement (Kanovska \& Tomaskova 2012). The most notable advances in this regard are associated with Narver and Slater (1990) and Kohli and Jaworski (1990). Kohli and Jaworski (1990) conceptualise market orientation from a behavioural perspective, which focuses on organisational activities pertaining to market intelligence generation of customer needs, disseminating of this information across individuals and departments and the organisation's responsiveness to market intelligence. Narver and Slater (1990) propose a cultural/attitudinal view, focusing on organisational norms and values that encourage behaviour consistent with market orientation, which entails customer orientation, competitor orientation and the degree of inter-functional coordination with all these components in an organisation. The perspectives from Kohli and Jaworski (1990) and Narver and Slater (1990) are complimentary to each other (Lafferty \& Hult 2001; Troilo 2006; Chin,Lo \& Ramayah 2013; Dubihlela 2013; Mokoena 2015).

Instead of viewing these two perspectives in isolation, a synthesis of both views are incorporated in the study in order to obtain a holistic assessment of market orientation.

The key market orientation components summarised from a review of literature are described briefly as:

- Customer orientation/responsiveness to customers: Activities that are geared to acquire information about customers to facilitate an understanding of the target markets' present and future needs and utilise its resources in order to create superior value for the target customers (Hult, Tomas, Ketchen \& Salter 
2005). The institution should respond to customer needs according to the collected and disseminated information (Rivera-Camino \& Ayala, 2010; Mei 2012).

- Competitor orientation/market intelligence generation/dissemination: Activities that are aimed to provide an understanding of key competitors (existing and prospective) and their environment (Kumar, Subramanian \& Strandholm 2011). Market information generation includes monitoring competitors' actions and the effects of other factors such as government regulation, technology and environmental forces that may impact on the institution (Frasen, Jaakkola \& Tikkanen 2015).

- Inter-functional coordination/information dissemination: This perspective focuses on business units or departments in an organisation in developing a system of effective communication and dissemination of market information (Peng \& George 2011). It mainly purports to improve the way the organisation is supposed to respond to its market (Akonkwa, 2013) through the coordinated use of resources in creating superior value to customers (Gotteland 2010).

- Responsiveness to market intelligence: Refers to the action taken in response to intelligence that is generated and disseminated (Zebal, 2003; Hafer \& Gresham 2008) in response to multiple societal demands (Akonkwa,2013).

\section{Barriers to Market Orientation}

Despite marketing principles being well established, HEIs attempting to implement the processes of market orientation often find their progress impeded by a variety of barriers (Cohen 2006; Simberova, Tomaskova \& Kanovska 2010; Mokoena 2015). From the 1950s onwards, varieties of studies have attempted to identify and analyse the effect of a number of specific barriers to developing market orientation (Felton 1959; Lear 1963; Chaganti \& Sambharya 1987; Tomaskova \& Kopfova 2011). It is worth mentioning that these studies identified multiple, intricate, interconnected barriers and often associate them with myths and misconceptions held by management regarding market orientation such as cultural barriers, organisational barriers and internal and external environmental barriers (Kanovska \& Tomaskova 2012). From a review of the literature, the barriers can be divided into three broad areas, namely the external environment, the operational environment and the internal environment.

The external environment factors are uncontrollable and difficult to eliminate by the institution itself (Hill \& Wright 2001), which inter alia include the state (government), the economy, market turbulence and technological changes (Pleshko \& Helens 2000; Zebal 2003; Qu \& Ennew 2003; Wang, Chen \& Chen 2012).

HEIs operate within a complex and turbulent market environment such as a recession that may decrease student enrolments and private funding, declining demand for certain programmes, which may make it uneconomical to continue with programmes. Both the pace and degree of innovation and changes in technology may induce technology and innovation uncertainty. Hence, HEIs that do not keep abreast with technology and innovation may have to relinquish their share of the market. Qu and Ennew (2003) identified policy and legislative measures of the government and excessive government regulations as impediments to market orientation. Zebal \& Goodwin (2012) affirm that the economic conditions (for example, inflation, unemployment levels and growth rate) of a country may impact on the spending power of key stakeholders.

Operational environment barriers exist at an operational level, are easier to manipulate and can be changed by an organisation (Aggarwal 2003; Tomaskova 2009). Operational environment barriers relate to the way in which an organisation is structured and has implications for the implementation of market orientation. Strategies to market orientation do not fail because they are weak, they fail because they do not fit well in existing departments or units or structures (Mbah, Ogbuehi \& Blankson 2007). The concentration of an organisation based purely on a cost-focused strategy was found to impede market orientation, whereas a cost and customer-oriented balance strategy contributes to a superior ability to recognise and respond to market conditions (Kumar et al. 2011).

Internal environment barriers, on the other hand, relate to management (especially top management) and employees and are easy to manage through a change in the mindset of various role players (Trueman 2004; Wang et al. 2012). The critical role of top management in fostering a market orientation is well recognised in the literature. The personality of top management, their management knowledge, skills and commitment impacts on the implementation of market orientation (Jaiyeoba 2013). Employees can also impede the implementation of market orientation and 
present themselves as a barrier. In this regard, employee apathy, ignorance and unwillingness to change appear to restrict market orientation activities (Zaman, Javaid, Arshad \& Bibi 2012).

\section{University Performance}

The importance of market orientation among universities stems from an underlying notion among marketing practitioners that it has a direct link with performance (Im \& Workman 2004; Kirca, Joyachandran \& Bearden 2005; Flavian \& Lozano 2006; Boohene, Agyapong \& Asomaning 2012; Shehu \& Mahmood 2014).

Given the major and rapid changes in South African HEIs, it is imperative to identify and monitor the consequences of market orientation. During the recent student protests across the country in October 2015, demanding a freeze on student fee increases, government summoned the minister of education to trim expenditures in universities so that they can assist in absorbing some of zero percent increase in student fees. The call for a cut on staff bonuses, a limit on the appointment of administrative staff, freeze on all new posts, review of the staff structure, extended use of computers and other technologies over their useful years and possible postponement of key projects may place further barriers for universities to achieve their performance outcomes. The Minister of Education in South Africa, Dr Nzimande, blamed some of the South African universities for the abuse of their institutional autonomy and pushed for the amendment of the Higher Education Act that would afford him greater say over how universities are run; this type of government interference clearly borders on university autonomy.

Further studies have demonstrated that a high degree of market orientation is associated with more outcomes that are favorable to organisational performance (Ghani \& Mahmood 2011; Altuntas, Semercioz \& Eregez 2013; Hussain, Shah \& Akhtar 2016 ).

\section{CONCEPTUAL FRAMEWORK AND HYPOTHESES DEVELOPMENT}

Based on the literature review, the following conceptual framework (Figure 1) is elucidated in order to examine the relationships among the variables used in the study.

Figure 1. Conceptual framework of relationships among the constructs

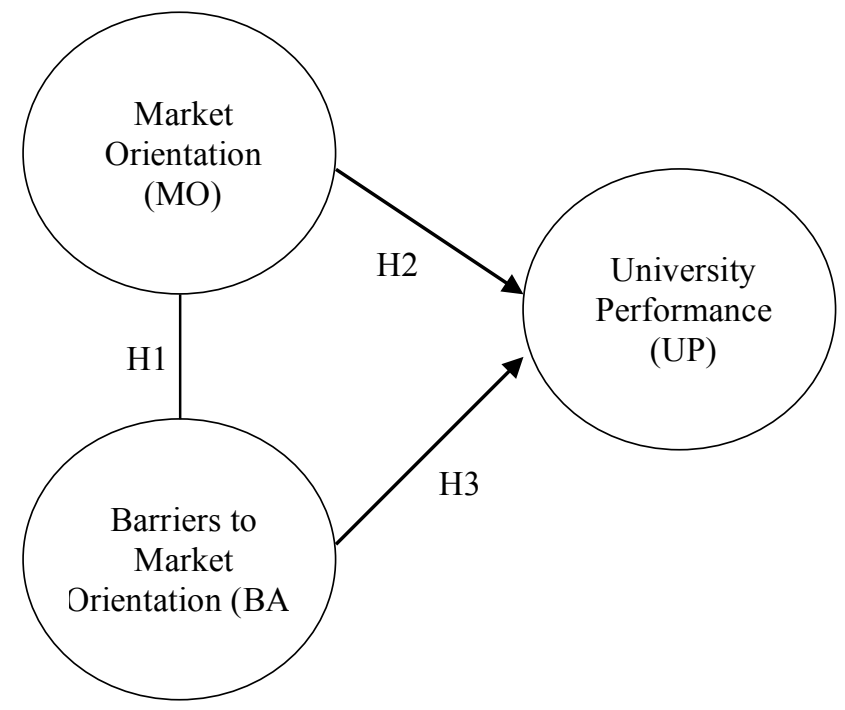

Based on the conceptual framework, the following hypotheses are formulated:

$\mathbf{H}_{1}$ : The barriers to market orientation will have a negative influence on market orientation.

$\mathbf{H}_{2}$ : Market orientation will have a positive influence on university performance.

$\mathbf{H}_{3}$ : The barriers to market orientation will have a negative influence on university performance 


\section{RESEARCH METHODOLOGY}

In line with previous studies, the study utilised a quantitative approach. The approach allows the use of questionnaires to collect data and control bias as the respondents were required to relate their own experiences and perceptions free from the researcher's intervention. In addition, the quantitative approach was chosen because it employs statistical methods to analyse data and is located within the domain of a post-positivism psychology. The survey method using a structured self-administered questionnaire was used to obtain information amongst academics within UoTs who participated in the study. This ensured high reliability as all participants were exposed to a standardised questionnaire.

\section{Sampling and Data Collection}

The study used a non-probability, convenient sampling technique. The survey was administered over a five-week period during April and May 2014 to fulltime academic employees. The study avoided part-time academics as this may have a tendency to distort the results of the study.

Prior to data collection, permission to conduct the study was sought from the respective research directorate offices of the UoTs. Of the 1250 questionnaires that were distributed, 528 questionnaires were returned of which 21 were unusable due to incomplete responses. Finally, 507 usable questionnaires were processed for data analysis. The participants were informed of the purpose of the survey prior to administration. Participation in the survey was voluntary and the respondents were assured of aspects regarding the anonymity and confidentiality of their responses. Because names or other identifiers (e.g. name of institution) were not required on the questionnaire, confidentiality and anonymity was assured. All data was computed in aggregate and not linked to any institution or respondent.

\section{Instrumentation}

Prior to finalising the questionnaire, pre-testing and piloting was conducted to refine the measuring instrument. The final questionnaire comprised a covering letter and four sections. Section A requested a biographical profile of the respondents and consisted mainly of multiple-choice questions and one dichotomous question with single answers. Sections B and C assessed market orientation variables and barriers to market orientation adapted from Zebal (2003). In Section D, university performance was measured by scales adapted from the studies of Ma and Todorovic (2011). Scale items for sections B, C and D were anchored on a five-point Likert format with responses ranging from 1= strongly disagree to $5=$ strongly agree.

\section{Reliability and Validity Assessments}

Internal consistency was evaluated by using Cronbach's coefficient alpha and composite reliability (CR) (Anderson $\&$ Gerbing 1988). The results of the reliability analysis are reported in Table 2. Cronbach alpha values exceeded the recommended threshold of 0.70 by Nunnally (1978), ranging from 0.728 to 0.904 , suggesting that all the items in the scale tap into the same underlying constructs (Hair, Anderson, Tatham, \& Black 2010). Furthermore, the composite reliability of all the constructs was greater than the minimum criteria of 0.70 recommended by Tustin, Ligthelm, Martins \& Van Wyk, (2010); Starkweather (2012). In addition, the item-to-total correlation values ranged from 0.507 to 0.830 , which is above the cut-off point of 0.5 as recommended by Hair, Black, Babin and Anderson (2010).

Various forms of validity were used in the study. Initially, the scales were examined for content validity by a panel of five academics during the pretesting stage and accordingly adapted for a UoT context. In the pretest stage, item wording changes and ambiguities were eliminated in the scale item construction. In the pilot test stage $\mathrm{n}=50$, the scale items were assessed by checking whether all items of each scale reflected an item-total correlation $>0.50$ on a construct (Sin, Tse, Heung \& Yim 2005). All scale items in the pilot stage were found to be acceptable.

In order to assess convergent validity, individual item loadings for each corresponding research construct were checked to ascertain whether they were above the recommended value of 0.5 (Anderson and Gerbing 1988). All the items had factor loadings of more than the recommended 0.5, indicating acceptable individual item convergent validity, as more than 50 percent of each item's variance was shared with its respective construct (Fornel \& Larcker 1981). 
Moreover, confirmatory factor analysis (CFA) was conducted for each of the three constructs in order to ascertain construct validity. All the AVE estimates, as shown in Table 2, reported higher than the threshold level of 0.50 and indicated validity for the various construct measures. Discriminant validity was established by checking if the AVE value was greater than the highest shared variance value (Fornell \& Larcker 1981). Table 2 shows that all the AVE values $(0.552,0.499$ and 0.595$)$ are above the SV values $(0.429,0.198$ and 0.429$)$ for all the research constructs, thereby confirming the existence of discriminant validity.

\section{RESULTS}

\section{Sample Composition}

The profile of the respondents is reported in Table 1.

Table 1. Profile of Respondents

\begin{tabular}{|c|c|c|c|c|}
\hline Demographic parameter & Classifications & $\mathbf{N}$ & n & $\%$ \\
\hline \multirow{2}{*}{ Gender } & Males & 507 & 289 & 57 \\
\hline & Females & & 218 & 43 \\
\hline \multirow{5}{*}{ Age group } & $<30$ years & 507 & 66 & 13 \\
\hline & 30-39 years & & 172 & 34 \\
\hline & $40-49$ years & & 160 & 32 \\
\hline & $50-59$ years & & 29 & 16 \\
\hline & $\geq 60$ years & & 28 & 5 \\
\hline \multirow{4}{*}{ Highest academic qualification } & Diploma/degree & 507 & 44 & 9 \\
\hline & First degree & & 197 & 39 \\
\hline & Masters & & 193 & 38 \\
\hline & Doctorate & & 71 & 14 \\
\hline \multirow{4}{*}{ Employed period } & $<3$ years & 507 & 71 & 14 \\
\hline & $3-6$ years & & 239 & 47 \\
\hline & $7-10$ years & & 126 & 25 \\
\hline & $\geq 10$ years & & 71 & 14 \\
\hline \multirow{3}{*}{ Current position } & Junior lecturer/lecturer & 507 & 246 & 49 \\
\hline & Senior lecturer/ associate professor & & 209 & 41 \\
\hline & HOD/dean/professor & & 52 & 10 \\
\hline \multirow{5}{*}{ Faculties of respondents } & Management Sciences & 507 & 188 & 37 \\
\hline & Engineering & & 112 & 22 \\
\hline & Humanities & & 101 & 20 \\
\hline & Applied Sciences & & 71 & 14 \\
\hline & Other & & 35 & 7 \\
\hline
\end{tabular}

An analysis of the demographic profile of respondents (Table 1) shows that the majority of respondents $(57 \% ; n=289)$ were male. In terms of the age groups, the largest group was composed of respondents who were aged between 30 and 30 years $(34 \% ; n=172)$. With reference to employment period, $47 \%(n=239)$ of the respondents had been employed as academics for periods ranging between three and six years. With regard to academic qualifications, 39\% ( $\mathrm{n}=197)$ of the respondents were holders of a first degree while $38 \%(\mathrm{n}=193)$ were holders of a Master's degree. In terms of their current occupational positions, $49 \%(\mathrm{n}=246)$ of the respondents were employed as either junior lecturers or lecturers. With regard to their faculties, $37 \%(n=188)$ of respondents were in Management Sciences, $22 \%(n=112)$ were in Engineering, 20\% ( $\mathrm{n}=101)$ were in Humanities and 14\% $(\mathrm{n}=71)$ were in Applied Sciences.

\section{Descriptive Statistics and Correlations}

To examine the perceptions of academics on market orientations, barriers and university performance variables, summated means and standard deviations were computed for each construct in order to ascertain respondents' agreement or disagreement to the various scale items. Non-parametric Spearman's correlations were also computed and compared among constructs in order to examine the direction and strength of relationships. Both these results are reported in Table 2. 
Table 2. Descriptive statistics and correlations among constructs

\begin{tabular}{l|c|c|c|c|c|}
\hline \multicolumn{1}{|c|}{ Research constructs } & MO & BA & UP & MEANS & SD \\
\hline Market orientation (MO) & $\mathbf{1}$ & & & 3.56 & 0.882 \\
\hline Barriers to market orientation (BA) & $-0.445^{* *}$ & $\mathbf{1}$ & & 3.46 & 0.878 \\
\hline University performance (UP) & $0.655^{* *}$ & $-0.455^{* *}$ & $\mathbf{1}$ & 3.55 & 1.058 \\
\hline
\end{tabular}

Note: ${ }^{* *}$ Correlation is significant at the 0.01 level ( 2 tailed)

\section{Measurement Model and Confirmatory Factor Analysis}

The data analysis was conducted following a two-step approach suggested by Anderson and Gerbing (1988). First, by validating the measurement model through confirmatory factor analysis (CFA) and secondly, by fitting the data through structural equation modeling (SEM). CFA was performed prior to testing the hypotheses in order to confirm accuracy of the multiple-item constructs. In addition, CFA was conducted to validate the research model with regard to model fit; CFA was used in this study because all of the latent constructs and corresponding measurements are derived from previous research and their reliability and validity were shown to be acceptable.

Acceptable model fit was confirmed by the chi-square value over degree of freedom $\left(\chi^{2} / \mathrm{df}\right)$ of 228.080 with 84 degrees of freedom at $\mathrm{p}<0.05$, whereby values between one and three show acceptable fit. Values of normed fit index (NFI), increment fit index (IFI), Tucker-Lewis index (TLI), comparative fit index (CFI), goodness-of-fit index (GFI) and adjusted goodness-of-fit index (AGFI) equal to or greater than benchmark value of 0.90 were considered acceptable. The root mean square error of approximation (RMSEA) value equal to or less than 0.08. was considered acceptable (Bagozzi \& Yi 1998; Hu \& Bentler 1999). Overall model fit measures were as follows: CMIN/df $=2.715$, NFI $=$ $0.957, \mathrm{IFI}=0.972, \mathrm{TLI}=0.960, \mathrm{CFI}=0.972, \mathrm{GFI}=0.945, \mathrm{AGFI}=0.911$ and $\mathrm{RMSEA}=0.058$. The CFA results provided by AMOS revealed that the overall fit of the measurement model was satisfactory (Fornell \& Larcker 1981).

Table 3. Composite reliability and accuracy analysis statistics

\begin{tabular}{|c|c|c|c|c|c|c|}
\hline \multirow[b]{2}{*}{ Research constructs } & \multicolumn{2}{|c|}{ Cronbach's alpha test } & \multirow[b]{2}{*}{$\mathbf{C R}$} & \multirow[b]{2}{*}{ AVE } & \multirow{2}{*}{$\begin{array}{l}\text { Factor } \\
\text { loading }\end{array}$} & \multirow{2}{*}{ Highest SV } \\
\hline & Item-total & Alpha value & & & & \\
\hline Market orientation & - & 0.900 & 0.896 & 0.552 & - & 0.429 \\
\hline MO1 & 0.830 & 0.926 & & & 0.648 & \\
\hline $\mathrm{MO} 2$ & 0.644 & 0.904 & & & 0.783 & \\
\hline MO3 & 0.756 & 0.840 & & & 0.703 & \\
\hline MO4 & 0.654 & 0.803 & & & 0.692 & \\
\hline MO5 & 0.715 & 0.859 & & & 0.810 & \\
\hline MO6 & 0.703 & 0.817 & & & 0.722 & \\
\hline MO7 & 0.671 & 0.910 & & & 0.821 & \\
\hline Barriers & - & 0.728 & 0.746 & 0.499 & - & 0.198 \\
\hline BA1 & 0.507 & 0.886 & & & 0.586 & \\
\hline BA2 & 0.555 & 0.769 & & & 0.772 & \\
\hline 215134397 & 0.601 & 0.826 & & & 0.746 & \\
\hline University performance & - & 0.904 & 0.898 & 0.595 & - & 0.429 \\
\hline UP1 & 0.741 & 0.886 & & & 0.729 & \\
\hline UP2 & 0.796 & 0.878 & & & 0.779 & \\
\hline UP3 & 0.703 & 0.891 & & & 0.717 & \\
\hline UP4 & 0.796 & 0.878 & & & 0.844 & \\
\hline UP5 & 0.764 & 0.882 & & & 0.838 & \\
\hline UP6 & 0.628 & 0.903 & & & 0.712 & \\
\hline
\end{tabular}




\section{Structural Model and Hypotheses Test}

The structural model was estimated to validate the proposed conceptual model. The structural model chi-square value over degree of freedom $\left(\chi^{2} / \mathrm{df}\right)$ was 218.529 with 82 degrees of freedom significant at $p=0.000<0.01$. The text output results for the structural equation model supported the adequacy of the proposed model: structural model fit: CMIN/df $=2.665 ; \mathrm{GFI}=0.948 ; \mathrm{AGFI}=0.914 ; \mathrm{CFI}=0.973 ; \mathrm{IFI}=0.974 ; \mathrm{TLI}=0.961 ; \mathrm{NFI}=0.958 ; \mathrm{RFI}=0.939 ; \mathrm{RMSEA}=$ 0.057. The structural path model is reported in Figure 2 and the results of the hypotheses are reported in Table 3 . The results suggest that the model converged well and could be a plausible representation of the underlying empirical data structures collected among UoTs.

Figure 2. Structural model of the relationship among constructs.

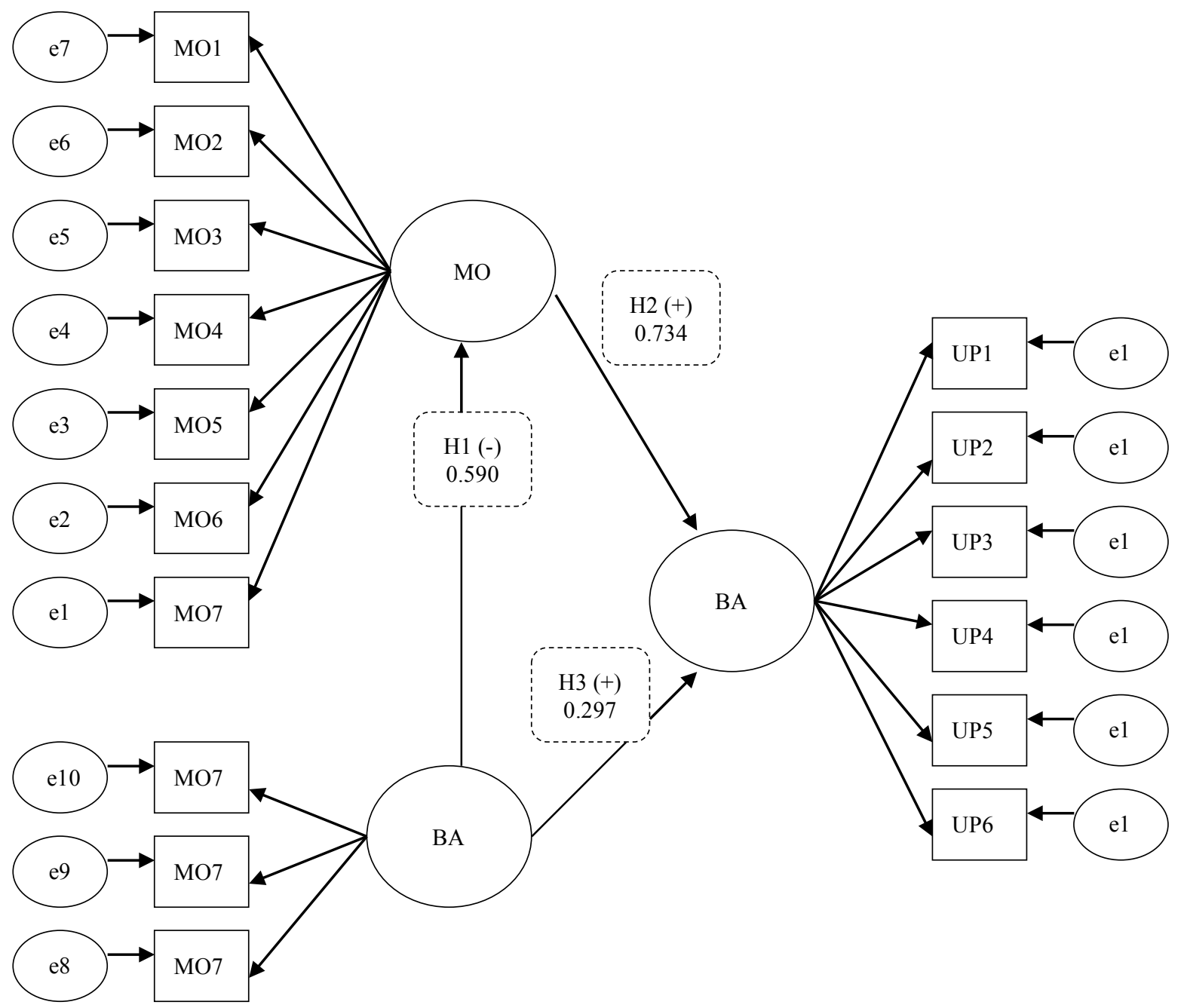

Note: $\mathrm{MO}=$ Market Orientation; $\mathrm{BA}=$ Barriers to Market Orientation; UP=University Performance

Results in Table 4 show that the proposed hypotheses (H1 to H3) were all supported. Individual hypothesis path coefficients of the modularised relationship outcomes were $-0.590,0.734$ and -0.237 for $\mathrm{H} 1, \mathrm{H} 2$ and $\mathrm{H} 3$ at the significance level of $<0.01$. In addition, the critical ratios reported were all greater than 1.96 . namely $\mathrm{H} 1=-9.405, \mathrm{H} 2$ $=10.247$ and $\mathrm{H} 3=-5.061$ and significant at $\mathrm{p}<0.01$. 
Table 4. Results of SEM analysis

\begin{tabular}{l|c|c|c|c|c}
\hline \multicolumn{1}{c|}{ Path } & Hypothesis & $\begin{array}{c}\text { Path coefficient } \\
\text { estimate }\end{array}$ & CR & P & Decision \\
\hline $\mathrm{BA} \rightarrow \mathrm{MO}$ & $\mathrm{H} 1$ & -0.590 & -9.405 & $* * *$ & Supported \\
\hline $\mathrm{MO} \rightarrow \mathrm{UP}$ & $\mathrm{H} 2$ & 0.734 & 10.247 & $* * *$ & Supported \\
\hline $\mathrm{BA} \rightarrow \mathrm{UP}$ & $\mathrm{H} 3$ & -0.297 & -5.061 & $* *$ & Supported \\
\hline
\end{tabular}

Note 1: *** p- value $0.01 ; 2$. Using a significance level of 0.05 critical ratios (t-value) that exceed 1.96 would be called significant. $\mathrm{BA}=\mathrm{Barriers}$ to market orientation $\mathrm{MO}=$ Market orientation $\mathrm{UP}=$ University performance

\section{DISCUSSION AND RECOMMENDATIONS}

With respect to descriptive statistics, Table 2 indicates that all mean scores returned for all the constructs were above the score of three on the Likert scale. The recorded means are 3.56, 3.46 and 3.55, suggesting that academics recognise the significance of these constructs within their institution. In addition, the standard deviations $(\mathrm{SD}=0.781, \mathrm{SD}=$ 0.776 and $\mathrm{SD}=1.120$ ) are also very similar across the constructs relative to the means.

In terms of the correlation analysis, significantly negative correlations $(r=-0.455 ; p=<0.01)$ were established between barriers of market orientation and university performance, as well as between barriers of market orientation and market orientation, thus confirming the negative impact of barriers to both market orientation and university performance constructs. However, a significant and positive correlation was revealed between market orientation and university performance $(\mathrm{r}=0.655 ; \mathrm{p}=<0.01)$. The degree to which market orientation is operationalised influences university performance.

The purpose of the current research was to examine the influence of market orientation and barriers to market orientation on university performance. In this endeavour, the first hypothesis postulated was the negative relationship between market orientation and barriers to market orientation. Consistent with hypothesis one (H1), results computed $(\beta=-.0590 ; \mathrm{t}=-9.405)$ indicate that there is a strong negative relationship between barriers to market orientation and elements of market orientation. The model converged with a proper solution and provided an estimate of the relationship between the constructs. Furthermore, it could be inferred from the results in Table 2 that the finding of a negative correlation between barriers and market orientation is intuitively correct and validates the hypothesis. Barriers to market orientation are associated with a low degree of implementation of the marketing concept. This supports the existence of barriers to market orientation identified by previous studies (Harris 2000; Slater 2001; Garver \& Gagnon 2002; Koprlova 2008; Kotler and Armstrong 2008; Kanovska 2012.). Dubihlela \& Dhurup (2015) and Mokoena, Mafini \& Dhurup (2015) further provide a practical insight into the barriers regarding the development of market orientation.

Hypothesis 2 postulated a positive relationship between market orientation and university performance. The standard coefficients $(\beta=0.734 ; \mathrm{t}=10.247)$ provided an affirmative response to Zebal and Goodwin's (2012:352) assertion that improved university performance is a consequence of higher levels of market orientation.

In addition, Carr and Lopez (2007), Ross (2013), Bak \& Olessen (2013), Alhakimi and Baharun (2010) and Mokoena (2015) have provided theoretical and empirical support to the view that higher levels of market orientation lead to higher levels of university performance.

Any university that has achieved a greater focus on students, other stakeholders and competitors, should accordingly achieve higher levels of performance (Webster, Hammond \& Rothwell 2010; Udoyi 2014). Algarni \& Talib (2014) further argue that market orientation provides a unifying focus for the efforts and projects of individuals and departments within HEIs in order to create superior value for customers, thus leading to superior performance.

As can be seen from Table 4 and Figure 2, the results provide evidence to support the third hypothesis. Hypothesis 3 (H3) postulates a negative influence of barriers to market orientation on university performance levels developed by UoTs from the sampling. Based on the standard coefficients of BA $\rightarrow \mathrm{UP}(\beta=-0.297 ; \mathrm{t}=-5.061)$ and SEM indexes found, the researcher is justified to attest to the validity of H3. Mokoena, Mafini \& Dhurup (2016) also confirmed the relationship between these mentioned variables. The outcome of this study, therefore, reinforces the negative 
association between the barriers to market orientation and university performance as found in previous studies (Hill \& Wright 2001; Zebal 2003; Cohen 2006; Keller 2008; Dubihlela 2013; Mokoena 2015). Therefore, H3 is supported.

Recommendations emanating from the studies include a market-oriented paradigm that should pervade the entire institution through recognition of market orientation as part of the institution's strategic planning. Commitment and communication from top management to all units to support marketing orientation is critical. To this end, policymakers and university support services should emphasise the market orientation strategy as a component of their advisory services.

The support of those making strategic decisions is needed to garner the necessary support to other employees in UoTs, especially top and senior management buy-in and support towards adoption and implementation of market orientation. Policymakers and university support services should strive to identify the conditions that foster or discourage market orientation and emphasise on the market orientation strategy as a component of their advisory services. In this regard, management of UoTs should create a culture and climate that maximises organisational learning, resource utilisation and capabilities to create superior university performance.

Specific directions and remedial actions should be tailored to deal with the different levels at which barriers exist. This includes development of a practitioner-oriented diagnostic and treatment tool to guide through the market orientation process. Best practices should distinguish between barriers impeding the adoption and implementation of market orientation on one hand, and those impacting upon the actioning of the planning outcomes on the other hand. In order to provide the expected results, it becomes imperative that UoTs should fundamentally rethink their policy framework and strategy by incorporating the marketing concept.

\section{IMPLICATIONS, LIMITATIONS AND FURTHER RESEARCH}

This study has academic and practical ramifications. On the academic front, a pioneering attempt was made to identify relationships between market orientation and university performance. This study specifically applies to UoTs and is supported by market theory. A practical implication with regard to managers, in order to achieve a higher level of university performance, is placing greater emphasis on market orientation. Other HEIs could learn from this study and utilise the research to diagnose and remedy barriers within their operational spheres.

Although this study has provided relevant and interesting insights into understanding the implementation of market orientation and its associated barriers to UoTs, it is critical to recognise the limitations associated with this study. Due to the selection of a non-probability convenience sampling, the generalisability of the findings beyond this specific category or setting was limited. The study had a retrospective focus, as the sample population was academics and thereby limited. The use of academics alone to measure the relationships among the constructs could have affected the validity of the responses. Academics might not have been fully aware of some or all market orientation practices and might have given inaccurate responses.

Further replication of the study is necessary to enhance external validity and include non-academics from more institutions such as comprehensive and traditional universities. A single cross-sectional research design was used in the study, which consequently lacked the depth of a longitudinal study. Therefore, a longitudinal study is recommended, as it would provide valuable information concerning any changes in the factors that determine the academic perceptions towards market orientation. All the data in the study were collected quantitatively, which led to the common method bias inherent to quantitative methods. Future studies can try to focus on triangulation methods to avoid this biasness.

\section{CONCLUSION}

The main reason for South African HEIs to adopt the marketing orientation concept relates to the recent concerns of the South African government regarding the enhancement of the development of HEIs under a new paradigm of marketisation. Today, most HEIs acknowledge the need for the philosophy of market orientation in order to survive and continue to face challenges in the academic environment. The initial reaction of universities towards this challenge is to adopt marketing theories with the scope of increasing the institutional performance. The presence of market 
orientation within UoTs would promote institutions that can deal with complexity and diversity to challenge conventional wisdom.

However, the traditional barriers hindering market orientation are still evident, even in HEIs that are exponents of the approach. Significant benefits could be derived from the implementation of market orientation in universities, like establishing partnerships with the business community. This study significantly contributes to the critical challenge facing HEIs, being to create the combination of the culture and the climate that maximises organisational learning, resources and capabilities to create superior university performance as prescribed by the DHET.

\section{AUTHOR BIOGRAPHIES}

BA Mokoena. Head of the Marketing Department, Faculty of Management Sciences, Vaal University of Technology, Private Bag X021, Vanderbijlpark, 1900, South Africa, E-mail: aubrey@vut.ac.za (corresponding author).

M Dhurup. Executive Dean Faculty of Management Sciences, Vaal University of Technology, Private Bag X021, Vanderbijlpark, 1900, South Africa, Corresponding author: manilalld@vut.ac.za

\section{REFERENCES}

Aggarwal, N. (2003). Organisational barriers to market orientation. Journal of Management Research, 3(2):87-97.

Akonkwa, D.B. 2013. Beyond market orientation: An operationalisation of stakeholder orientation in higher education African Journal of Marketing Management Vol. 5(3), pp. 68-81,

Algarni, M.A. \& Talib, N.A. 2014. A Framework of Measuring the impact of Market Orientation on the outcome of Higher Education Institutions mediated by innovation. International Review of Management and Business Research, 3(2), 607624.

Alhakimi, W. \& Baharun, R. (2010). An integrative model of market orientation constructs in consumer goods industry: an empirical evidence. International Management Review, 6(2) 40-54.

Altuntas G, Semercioz, F. \& Eregez, H. (2013). Linking strategic and market orientations to organizational performance: the role of innovation in private healthcare and organizational performance: The moderating role of service quality. SAGE Open, 3, 1-14.

Anderson, J.C. \& Gerbing, D.W. (1988). Structural equation modelling in practice: a review and recommended two-step approach. Psychological Bulletin, 103(3) 411-423.

Bagozzi, R.P. \& YI, Y. (1998). On the evaluation of structural equation models. Journal of the Academy of Marketing Science, 16 74-94.

Bak-Olesen, N. (2013). Proactive Market Orientations Effect on Export Performance,” doctoral dissertation, Stud. Bsc. In Economics \& Business Administration, Aarhus University: Denmark.

Becher, R.C., Halstead, D. \& Haynes, P. (2003). Marketing orientation in SMEs: effects of the internal environment. New England of Entrepreneur, 6(1) 13-22.

Boohene, R., Agyapong D. \& Asomaning R. (2012) A Micro Level Analysis of the Market Orientation - Small Business Financial Performance Nexus American International Journal of Contemporary Research, 2(1).

Brown, R. \& Carasso, H. (2013). Everything for Sale? The Marketisation of UK Higher Education. London and New York: Routledge

Brown, R. (2006). Higher education and the market: further thoughts and reflections, Oxford Centre for Higher Education Policy Studies, Occasional Paper Number 24, [online] http://oxcheps.new.ox.ac.uk/MainSite\%20pages/papers.html

Brown, R. (2015). The marketisation of higher education: issues and ironies. New Vistas, 1(1).

Camelia, G \& Marius, P. (2013). Incorporating market orientation in higher education. Doctoral Doctor of Philosophy thesis in School of Economics and Business Administration. Babes-Bolyai University, Cluj-Napoca: Romania.

Carr, J.C. \& Lopez, T.B. (2007). Examining market orientation as both culture and conduct: modelling the relationships between market orientation and employees responses. The Journal of Marketing Theory and Practice, 15(2): 113-125.

Chaganti, R. \& Sambharya, R. (1987). Strategic orientation and characteristics of top management. Strategic Management Journal, 8, 393-401.

Chin, C.H., Lo, M.C. \& Ramayah, T. (2013) Market orientation and organisational performance. The Moderating Role of Service Quality. Sage Publication, 1-14.

Cohen, G.T. (2006). Barriers to marketing within professional service firms: a study of the understanding and application of marketing within accountancy and law. Doctor of Philosophy Thesis, Brunel Business School, Brunel University, 1356.

Dubihlela, J. (2013). Determinants of market orientation adoption among small medium enterprises (SMES) in South Africa. Mediterranean Journal of Social Sciences, 4(6), 55-65. 
Dubihlela, J. \& Dhurup, R. (2015). Determinants Of, And Barriers To, Market Orientation and the Relationship with Business Performance among SMEs. The Journal of Applied Business Research 31(5), 1667-1678.

Felgueira, T. \& Rodrigues, R.G. (2014). Market orientation of teachers and researchers in higher education institutions: a new approach. Procedia-Social and Behavioural Sciences, 174(2015), 3017-3024.

Felton, A.P. (1959). Making the marketing concept work. Harvard Business Review, 37(4) 55-65.

Flavian, C. \& Lozano, J. (2006). Organisational antecedents of market orientation in the public university system. International Journal of Public Sector, 19(5), 447-467.

Fornell, C. \& Larcker F (1981). Education SEM with unobservable variables and measurement error. Journal of Marketing Research, 18(1), 39-50.

Frosen, J.J., Luoma, M., Jaakkola, H. \& Aspara, J.T. (2016). What counts versus what can be the counted: the complex interplay of market orientation and marketing performance measurement. Journal of Marketing, DOI: 10.1509/15.013

Gajić, J. (2012). Importance of marketing mix in Higher Education Institutions. Singidunum Journal, 9(1), 29-41.

Garver, M.S. \& Gagnon, G. (2002). Seven keys to improving customer satisfaction programs. Business Horizons, 16(2), $35-42$.

Ghani, U. \& Mahmood, Z. (2011). Antecedents of Market Orientation in the microfinance in industry of Pakistan. African Journal of Business Management, 5(5), 1822-1831.

Gotteland, D. \& Haon, C. (2010). The relationship between market orientation and new product performance: The forgotten role of development team diversity. Marketing Letters, 20 (1), 75-89

Hafer, J. \& Gresham, G.G. (2008). Organizational Climate Antecedents to the Market Orientation of Cross-Functional New Product Development Teams Institute of Behavioral and Applied Management. 2008, 184-205.

Hair, J.F., Anderson, R.E., Tatham, R.L. \& Black, W.C. (1992). Multivariate data analysis with readings. $3^{\text {rd }}$ ed. New York: McMillan Publishing Company.

Hanover 2014 Understanding Strategic Marketing - Market Orientation, Strategy and Firm Performance of Marketing and Management, Leibniz University: Hannover.

Haon, C. (2010). The Relationship between Market Orientation and New Product Performance: The Forgotten Role of Development Team Diversity. International Journal of Research in Marketing, 23 (2), 171-185.

Harris, L.C. (2000). The organizational barriers to developing market orientation. European Journal of Marketing, 34(5/6) 598624.

Harris, H (2008). The organisational barriers to developing market orientation European Journal of Marketing 34(5/6), 598-624.

Hill, J. \& Wright, L.T. (2001). Quantitative research agenda from small to market sized enterprise marketing intelligence and planning 19(6), 432-443. http://www.kamsconference.org/

Hult, G., Tomas, M. \& Ketchen, D.J. \& Slater, S.F. (2005). Market orientation and performance: an integration of disparate approaches. Strategic Management Journal, 26(12), 1173-81.

Hussain, J., Shah, F.A. \& Akhtar, C.S. (2016). Market Orientation and Organizational performance in small and medium sized enterprises. A conceptual approach. City University Journal, 06(01), 166-180.

Im, S. \& Workman, J.P. (2004). Market orientation, creativity and new product performance in high-technical firms. Journal of Marketing, 68 114-132

Jaiyeoba, O.O. (2013). Performance Outcome of Market Orientation Behaviours among Botswanas' Small Service Firms. Journal of Management Research, 6(1), 52 -71.

Ionescu, A. (2015). The relationship between the innovation orientation and organizations' performance in Romania. Romanian Journal of Economics, 40, (49), 299-312.

Ivy, J. (2008). A new higher education marketing mix: the 7Ps for MBA marketing. International Journal of Educational Management, 22(4), 288-299.

Kanovska, L. \& Tomaskova, E. (2012). Interfunctional coordination at hi-technical firms. Engineering Economics, 23(1), 70-76.

Keller, K.L. (2008). Strategic brand management. 12 th ed. New Jersey: Prentice-Hall.

Kirca, A.H, Joyachandran, S. \& Bearden, W.O. (2005). MO: a meto-andylic review and assessment of its antecedents and impact on performance. Journal of Marketing, 69(2), 24-41.

Kohli, A.K. \& Jaworski, B.J. (1990). Market orientation: the construct, research propositions, and managerial

Kotler, P. \& Armstrong, G. (2008). Principles of marketing. 12th ed. Englewood Cliffs, NJ: Prentice Hall.

Kotler, P. (1972). A generic concept of marketing. Journal of Marketing, 36(2) 46-54.

Kumar, K., Subramanian, R. \& Strandholm, K. (2011). Market orientation and performance: Does organizational strategy matter?

Kumar, A. \& Hurwitz (2015). Supply and Demand in the Higher Education Market: College Enrollment College Board Research Brief, February 2015 1-11

Kusumawati, A. (2010). Privatisation and marketisation of Indonesian public universities: a systematic review of student choice criteria literature Available on Research Online: http://ro.uow.edu.au/gsbpapers/32 University of Wollongong

Lafferty, B. \& Hult, G.T.M. (2001). A synthesis of contemporary market orientation perspectives. European Journal of Marketing, 35(1/2) 92-109.

Lear, R.W. (1963). No easy road to market orientation. Harvard Business Review, 41(5), 73-80 Management, $13(5), 366$ - 381.

Ma, J. \& Todorovic, Z. (2011). Making university relevant: MO as a dynamic capability within institutions of higher learning. Academy of Marketing Studies Journal, 15(2), 1-15.

Mbah, C., Ogbuehi, A. \& Blankson, C. (2007). The Challenges of Market Orientation Strategies Implementation in an Emerging 
Economy. Journal of Business Case Studies - Second Quarter 2007, 3(2), 29-42

Mei, C., Morgan, R.E. \&. Robson, M.J. (2012). Strategic Orientation and New Product Success: exploring Chinese HighTechnology Ventures. Journal of Strategic Marketing, 20(3), 267-286

Mokoena, B.A. (2015). Marketing of Universities of Technology: examining the relationship between market orientation elements, barriers and university performance. Unpublished Doctoral Thesis Vaal University of Technology.

Mokoena, B.A., Mafini, C. \& Dhurup, M. (2015). Navigating the influence of marketing orientation on University performance. Studia Universities' Babes-Bolyai, Oeconomica, 60(3), 22-40.

Nunnally, J.C. (1978). Psychometric theory. New York: McGraw-Hill.

Pleshko, L.P. \& Herens. R.A. (2000.) Customer- focus or competitor-Focus? A financial services example. Journal of Professional Services Marketing, 20(2), 19-32.

Qu, R. \& Ennew, C.T. (2003). Developing a market orientation in transitional economy: the role of government regulations and ownership structure. Journal of Public Policy and Marketing, 24(1), 82-89.

Rivera-Camino, J., \& Ayala, V. M. B. (2010). Market orientation at universities. Construct and exploratory validation. Innovar, 20(36), 125-138. Retrieved from

http://www.scopus.com/inward/record.url?eid=2-s2.0-

Ross, G. (2013). Come on Higher Ed...Get with the Programme! A Study of Market Orientation in International Student Recruitment

Schuller, D. \& RastIcova, M. (2011). Marketing communication mix of universities communicating with students in an increasing competitive University environment. Journal of competitiveness, (3):58-71.

Trueman, K. (2004). Market-orientation and local government. Barriers and constraints. Political Studies Association, (1) 1-12.

Tustin, D., Ligthelm, A., Martins, D. \& Van Wyk, J. (2010). Marketing research in practice. Pretoria: UNISA Press.

Udoyi 2014) CO Relationship between market orientation and performance of commercial banks in Kenya University of Nairobi Unpublished Thesis for Master of Business Management validation. Innovar, 20(36), 125-138. Retrieved from http://www.scopus.com/inward/record.url?eid=2-s2.0-

Wang, C., Chen, K. \& Chen, S. (2012). Total quality management, market orientation and hotel performance: The moderating effects of external environmental factors. International Journal of Hospitality Management, 31

Webster, R.L., Hammond, K.L. \& Rothwell, J.C. (2010) Customer and Marketinng Orientation within AACSB Member Business Schools: Comparative Views from three Levels of Administrators. American Journal of Business Education, 3,

Zaman, K., Javaid, N., Arshad, A., Bibi, S. (2012). Impact of Internal Marketing on Market Orientation and Business Performance. In International Journal of Business and Social Science, 3(12), 76-87.

Zebal, M.A. \& Goodwin, D.R. (2012). Market orientation and performance in private universities. Marketing Intelligence and Planning, 30(3), 339-357.

Zebal, M.A. (2003). A synthesis model of market orientation for a developing country: the case of Bangladesh, PhD Thesis Victoria University of Technology: Melbourne Australia. 


\section{NOTES}

